\title{
Proline-Specific Fungal Peptidases: Genomic Analysis and Identification of Secreted DPP4 in Alkaliphilic and Alkalitolerant Fungi
}

\author{
Nikita Alkin ${ }^{1}$, Yakov Dunaevsky ${ }^{2, *}$, Elena Elpidina ${ }^{2}$, Galina Beljakova ${ }^{1}$, Valeria Tereshchenkova ${ }^{3}$, \\ Irina Filippova ${ }^{3}$ and Mikhail Belozersky ${ }^{2}$ \\ 1 Biological Faculty, Lomonosov Moscow State University, 119991 Moscow, Russia; nikita9801@mail.ru (N.A.); \\ adm-odo@yandex.ru (G.B.) \\ 2 A.N. Belozersky Institute of Physico-Chemical Biology, Lomonosov Moscow State University, \\ 119991 Moscow, Russia; elp@belozersky.msu.ru (E.E.); mbeloz@belozersky.msu.ru (M.B.) \\ 3 Chemical Faculty, Lomonosov Moscow State University, 119991 Moscow, Russia; \\ lerunechka_lu@mail.ru (V.T.); irfilippoff@yandex.ru (I.F.) \\ * Correspondence: dun@belozersky.msu.ru
}

Citation: Alkin, N.; Dunaevsky, Y.; Elpidina, E.; Beljakova, G.; Tereshchenkova, V.; Filippova, I.; Belozersky, M. Proline-Specific Fungal Peptidases: Genomic Analysis and Identification of Secreted DPP4 in Alkaliphilic and Alkalitolerant Fungi. J. Fungi 2021, 7, 744. https://doi.org/ 10.3390/jof7090744

Academic Editors: Paul

Olusegun Bankole and

Dietmar Schlosser

Received: 13 August 2021

Accepted: 7 September 2021

Published: 10 September 2021

Publisher's Note: MDPI stays neutral with regard to jurisdictional claims in published maps and institutional affiliations.

Copyright: (c) 2021 by the authors. Licensee MDPI, Basel, Switzerland. This article is an open access article distributed under the terms and conditions of the Creative Commons Attribution (CC BY) license (https:// creativecommons.org/licenses/by/ $4.0 /)$.
Abstract: Proline-specific peptidases (PSP) play a crucial role in the processing of fungal toxins, pheromones, and intracellular signaling. They are of particular interest to biotechnology, as they are able to hydrolyze proline-rich oligopeptides that give a bitter taste to food and can also cause an autoimmune celiac disease. We performed in silico analysis of PSP homologs in the genomes of 42 species of higher fungi which showed the presence of PSP homologs characteristic of various kingdoms of living organisms and belonging to different families of peptidases, including homologs of dipeptidyl peptidase 4 (DPP4) and prolyl aminopeptidase 1 found in almost all the studied fungal species. Homologs of proliniminopeptidases from the S33 family absent in humans were also found. Several studied homologs are characteristic of certain taxonomic groups of fungi. Phylogenetic analysis suggests a duplication of ancestral DPP4 into transmembrane and secreted versions, which predate the split of ascomycete and basidiomycete lineages. Comparative biochemical analysis of DPP4 in alkaliphilic and alkali-tolerant strains of fungi showed that, notwithstanding some individual features of these enzymes, in both cases, the studied DPP4 are active and stable under alkaline conditions and at high salt concentrations, which makes them viable candidates for biotechnology and bioengineering.

Keywords: ascomycetes; alkaliphilic and alkali-tolerant fungi; basidiomycetes; bioinformatic analysis; proline-specific peptidases; secretion

\section{Introduction}

Fungi occupy various ecological niches, owing to their remarkable physiological plasticity. For example, several fungal species thrive in extreme temperatures and harsh radiation [1-4]. The extremophilic groups of fungi also include fungi of alkaline habitats that can grow and develop at a $\mathrm{pH}$ of 10 or higher $[5,6]$. The survival of fungi depends on their ability to use nutrients from living or dead organic materials. The encoded set of enzymes largely determine the habitat these fungi can occupy. Thus, differences in secreted enzymes can significantly affect their ability to colonize plants and animals. The peptidases secreted by fungi, performing trophic functions, cleave the bonds in protein substrates and lead to the formation of amino acids and peptides, which are absorbed by fungal cells and used in catabolic and biosynthetic processes.

Secreted peptidases from alkaliphilic fungi are of significant interest to biotechnology [7]. The turn of the 20th and 21st centuries saw expanding practical use of alkaliphilic bacterial enzymes, which served as a starting point for research on the physiology and biochemistry of fungi in alkaline habitats. Among the currently known groups of alkaliphilic 
and alkali-tolerant fungi, the family Plectosphaerellaceae takes a special place [8]. Representatives of this family have a wide range and are described in detail both taxonomically and physiologically; the genome of one of them (Sodiomyces alkalinus) is fully sequenced [9]. However, little is known about the biochemistry of these fungi. The diversity and functioning of the enzymes in these fungi, in particular, to date, highly specific enzymes, such as proline-specific peptidases (PSP), have not been analyzed in this family of fungi.

The proline imino group, unique to proteinogenic amino acids, is a part of the pyrrolidine ring, which renders the peptide bonds formed by proline amino acid residues highly resistant to the effects of classical peptidases. Proteins with a high proline content and proline-containing peptides are among the most significant for metabolism, nutrition, and cellular recognition, in particular, of intracellular signal transmission [10]. Many structural and storage proteins and peptides contain proline, the physiological need for which remains high throughout the life cycle [11]. PSPs are produced by bacteria, archaea, and eukaryotes to break down proline-rich proteins and peptides that are difficult to hydrolyze. Apart from them, two nonspecific enzymes, leucine aminopeptidase (LAP) and cytosolic nonspecific dipeptidase (CND), are able to cleave off the N-terminal Pro.

The practical interest in PSP is largely associated with their possible application to produce gluten-free products, as well as medicines to treat certain gastrointestinal diseases. Among the storage proteins of monocotyledonous seeds used for food by humans and animals, a large group of proteins has a high proline content (more than 30\%). These are the so-called gluten proteins (in particular, prolamins), which are often the main food source, but the proline-rich peptides formed from them during incomplete digestion cause the autoimmune celiac disease in sensitive people. The use of commercially available PSPs from various sources to neutralize the immunogenic potential of proline-rich gluten peptides could be one of the main applications of their unique specificity and an attractive option for patients with celiac disease. Oral enzyme therapy using such gluten-destroying enzymes appears to be a promising therapeutic approach. While the PSPs of bacteria [12] and animals [13] are characterized in detail, the data on the PSP of fungi are limited to studies of prolyl endopeptidase from Aspergillus niger [14], Flammulina velutipes [15], and A. oryzae [16].

The aim of this work is to evaluate the potential of fungi in the production of various types of PSP using a bioinformatic approach, followed by the biochemical identification of PSP in the culture of fungi, as well as to characterize their properties that determine the possibility of their further use. Fungi growing under extreme conditions are of scientific interest, both for studying the adaptive evolution of fungi and for evaluating their potential as producers of commercially valuable enzymes. Therefore, we tried to use representatives of the Plectosphaerellaceae family, on the one hand, as a source of enzymes capable of cleaving complex proline-containing bonds, and on the other hand, we tried to compare the production of enzymes and their properties in two groups of fungi-alkaliphiles and alkali-tolerants.

\section{Materials and Methods}

\subsection{Materials}

Culture medium components-malt extract (Maltax 10), (Senson, Niemenkatu, Finlandia), yeast extract (Biomedicals LLC, Santa Ana, CA, USA), casein (Merck, Darmstadt, Germany), peptone (TM-Media, Delhi, India); substrate Ala-Pro- $p$ Na was synthesized according to standard procedures [17] in the Protein Chemistry Laboratory, Faculty of Chemistry, Moscow State University; inhibitors-PMSF(Serva, Heidelberg, Germany), diprotin A and diprotin B (Bachem, Bubendorf, Switzerland), sitagliptin and vildagliptin (BioVision, Milpitas, CA, USA), ethylenediaminetetraacetic acid (EDTA) (Merck, Darmstadt, Germany), iodoacetamide (Merck, Darmstadt, Germany). 


\subsection{In Silico PSP Analysis}

Analyzed peptidases:

Prolyl oligopeptidase (POP), prolidase (XPD), fibroblast activation protein (FAP), dipeptidyl peptidases (DPP)4, DPP6, DPP8, DPP9, DPP10, X-Pro aminopeptidases (APP)1 and APP2, acid prolyl endopeptidase (EPR) from Aspergillus niger, prolyliminopeptidases from Aeromonas sobria (PIP1), from Lactobacillus delbrueckii (PIP2), and from carrot (Daucus carota, PIP3), leucine aminopeptidase (LAP), and cytosolic nonspecific dipeptidase (CND).

A total of 42 species of dikaryomycetes with a sequenced genome, including the S. alkalinus alkaliphile (Table 1), were selected from the NCBI database. The presented set of species includes representatives of all 6 subdivisions of higher fungi, as well as representatives of various morphological groups (yeast, mycelial fungi, lichenized fungi) and ecological-trophic groups (humus saprotrophs, xylotrophs, phytopathogens, entomopathogens). In each of the selected genomes, homologs of the known 12 human PSP (CND-NP_001161971.1 (presents the sequence numbers from GenBank that were used as a request), LAP-NP_056991.2, POP-NP_002717.3, XPD—AAA60064.1, FAPNP_001278736.1, DPP4-NP_001366533.1, DPP6-NP_001034439.1, DPP8—XP_016877870.1, DPP9-NP_001371540.1, DPP10-NP_001171507.2, APP1-XP_016872104.1, and APP2NP_003390.4), as well as those of acid EPR_XP_025457004.1 from Aspergillus niger, of PIP1 from Aeromonas sobria-BAA06380.1, from Lactobacillus delbrueckii (PIP2)—AAA61596.1, and from carrot (Daucus carota, PIP3-KZM82276.1), were searched by amino acid sequences using the Protein BLAST service [18]. The cut-off threshold was E-value 1 * 10-20 and $75 \%$ coverage. To improve the homology attribution accuracy of the detected sequences, clustering of all sequences using the EFI-EST service was used [19]. The following parameters were further calculated for each homolog: molecular weight, number of amino acids, and isoelectric point using the online resource Isoelectric Point Calculator [20]; presence, size, and position of the signal peptide; and transmembrane domain (Signal P-5.0 and TMHMM Server V. 2.0 services) [21]. After that, the amino acid sequences of the detected PSP homologs were aligned using the MEGA X package. In the Batch CD-Search service [22], a search was performed for conservative domains of the PSP homologs. For the most common DPP4 peptidase, a phylogenetic tree of homologs was constructed using the MEGA X ML package. The DPP4 amino acid sequence of humans (Homo sapiens) was selected as an outgroup.

Table 1. Profile of PSP homologs in the genomes of higher fungi. The table cells contain the number of homologs.

\begin{tabular}{|c|c|c|c|c|c|c|c|c|c|c|c|}
\hline Taxon & Species & APP1 & CND & DPP4 & EPR & LAP & PIP1 & PIP2 & PIP3 & POP & $\overline{X P D}$ \\
\hline \multirow{2}{*}{ Taphrinomycotina } & Taphrina deformans & 1 & 2 & 1 & 1 & & 1 & & & & 1 \\
\hline & Saitoella complicata & 1 & 2 & 1 & & 1 & 1 & & 1 & 1 & 2 \\
\hline \multirow{4}{*}{ Saccharomycotina } & Saccharomyces cerevisiae & 1 & 2 & 2 & & & & & & & 2 \\
\hline & Wickerhamomyces anomalus & 1 & 2 & 3 & & & & & & & 2 \\
\hline & Candida albicans & 3 & 2 & 2 & & & 1 & & & & 2 \\
\hline & Yarrowia lipolytica & 1 & 3 & 2 & & & 1 & & & & 2 \\
\hline
\end{tabular}


Table 1. Cont.

\begin{tabular}{|c|c|c|c|c|c|c|c|c|c|c|c|}
\hline Taxon & Species & APP1 & CND & DPP4 & EPR & LAP & PIP1 & PIP2 & PIP3 & POP & XPD \\
\hline \multirow{27}{*}{ Pezizomycotina } & Mycosphaerella graminicola & 1 & 2 & 2 & 10 & & 1 & 1 & 1 & & 3 \\
\hline & Ascosphaera apis & & 2 & 1 & 1 & & 1 & & & & 3 \\
\hline & Aspergillus fumigatus & 1 & 2 & 2 & 3 & & 1 & & & & 3 \\
\hline & Penicillium chrysogenium & 1 & 2 & 1 & 1 & & 1 & & 1 & & 3 \\
\hline & Coccidioides immitis & 1 & 1 & 2 & 2 & & & & & & 2 \\
\hline & Endocarpon pusillum & 1 & 2 & 1 & 1 & & 1 & & & & 2 \\
\hline & Blumeria graminis & 1 & 2 & 1 & 2 & & 1 & & 1 & & 1 \\
\hline & Botrytis cinerea & 1 & 3 & 1 & 2 & & 1 & 1 & & & 3 \\
\hline & Drechslerella stenobrocha & 1 & 1 & 2 & 4 & & & & & & 2 \\
\hline & Colletotrichum tofieldiae & 1 & 4 & 2 & 3 & & 1 & 1 & & & 3 \\
\hline & Sodiomyces alkalinus & 1 & 2 & 2 & 1 & & & & & & 3 \\
\hline & Claviceps purpurea & 1 & 2 & 1 & 3 & & 1 & & & & 3 \\
\hline & Hypocrella siamensis & & & 2 & & & & & & & \\
\hline & Metarhizium anisopliae & 1 & 2 & 2 & 4 & & 1 & & & & 3 \\
\hline & Moelleriella libera & 1 & 2 & 1 & 3 & & 1 & & & & 3 \\
\hline & Pochonia chlamydosporia & 1 & 2 & 2 & 4 & & 1 & & & & 4 \\
\hline & Beauveria bassiana & 2 & 2 & 2 & 4 & 1 & 1 & & & 1 & 3 \\
\hline & Cordyceps confragosa & 3 & 3 & 4 & 8 & & 1 & & & & 5 \\
\hline & Isaria fumosorosea & 1 & 2 & 2 & 5 & & 1 & 1 & & & 3 \\
\hline & Torrubiella hemipterigena & 1 & 2 & 3 & 14 & & 1 & 1 & & & 3 \\
\hline & Fusarium langsethiae & 1 & 2 & 2 & 2 & & 1 & & & & 3 \\
\hline & Fusarium poae & 1 & 2 & 2 & 1 & & 1 & & & & 3 \\
\hline & Nectria haematococca & 1 & 3 & 2 & 1 & & 1 & & & & 4 \\
\hline & Gaeumannomyces tritici & 1 & 2 & 2 & 5 & & 2 & & & & 3 \\
\hline & Magnaporthe oryzae & 1 & 2 & 2 & 6 & & 1 & & & & 3 \\
\hline & Magnaporthiopsis poae & 1 & 3 & 2 & 4 & & 1 & & & & 1 \\
\hline & Sporothrix insectorum & & 2 & 1 & 4 & & 2 & 1 & & & 1 \\
\hline Pucciniomycotina & Puccinia graminis & 1 & 1 & 1 & & 1 & & & 2 & 1 & 2 \\
\hline \multirow{3}{*}{ Ustilaginomycotina } & Tilletia indica & 1 & 2 & 1 & 1 & 1 & & & 1 & 1 & 1 \\
\hline & Pseudozyma hubeiensis & 2 & 2 & 1 & 1 & 1 & & & 1 & 1 & 1 \\
\hline & Ustilago zeae & 2 & 2 & 1 & 1 & 1 & & & 1 & 1 & 1 \\
\hline \multirow{5}{*}{ Agaricomycotina } & Amanita muscaria & 2 & 2 & 1 & 3 & 1 & & & 3 & 1 & 2 \\
\hline & Agaricus bisporus & 1 & 2 & 1 & 1 & 2 & 1 & 4 & 2 & 1 & 2 \\
\hline & Lentinula edodes & 2 & 2 & 1 & 2 & 1 & 1 & 4 & 1 & 1 & 2 \\
\hline & Daedalea quercina & 2 & 2 & 1 & 3 & 1 & & 8 & 1 & 1 & 2 \\
\hline & Calocera cornea & 2 & 2 & 1 & 3 & 1 & & 7 & 1 & 1 & 2 \\
\hline
\end{tabular}

APP1—X-Pro aminopeptidase; CND—cytosolic nonspecific dipeptidase; DPP4—dipeptidyl peptidase; EPR—acid prolyl endopeptidase from As. niger; LAP-leucine aminopeptidase; PIP1—-prolyliminopeptidase from A. sobria; PIP2-prolyliminopeptidase from L. delbrueckii; PIP3-prolyliminopeptidase from D. carota; POP—prolyl oligopeptidase; XPD_prolidase.

\subsection{Fungal Strains}

Five species of alkaliphilic and alkali-tolerant ascomycetes from the family Plectosphaerellaceae (Glomerellales; Sordariomycetes) and one alkali-tolerant species from the family Hypocreaceae (Hypocreales; Sordariomycetes) were studied. Each species was represented by one strain (Sodiomyces magadiensis was represented by two strains), obtained from the collection of the Department of Mycology and Algology of the Lomonosov Moscow State University. The cultures are listed in Table 2. 
Table 2. Cultures used for analysis of activity.

\begin{tabular}{|c|c|c|c|}
\hline Species & Strains & The Gathering Place & Relation to $\mathrm{pH}$ \\
\hline Acrostalagmus luteoalbus & $\begin{array}{c}\text { V205 } \\
(\text { CBS 137625) }\end{array}$ & Kulundinskaya steppe; lake & alkalitolerant \\
\hline Chordomyces antarcticus & $\begin{array}{c}\text { M27 } \\
(\text { CBS 120045) }\end{array}$ & Kulundinskaya steppe; lake & alkalitolerant \\
\hline Sodiomyces alkalinus & $\begin{array}{c}\text { F11 } \\
(\text { CBS 110278) }\end{array}$ & Mongolia; lake & alkalophile \\
\hline \multirow{2}{*}{ Sodiomyces magadiensis } & $\begin{array}{c}\text { MAG5 } \\
\text { (CBS 142933) }\end{array}$ & $\begin{array}{l}\text { Kenya, soda soil on the shore of the } \\
\text { lake Magadi }\end{array}$ & alkalophile \\
\hline & $\begin{array}{c}\text { B39 } \\
(\text { CBS 142937) }\end{array}$ & $\begin{array}{l}\text { Russia; saline soil on the shore of the } \\
\text { lake Baskunchak }\end{array}$ & alkalophile \\
\hline Sodiomyces tronii & $\begin{array}{c}\text { MAG3 } \\
(\text { CBS 137620) }\end{array}$ & Kenya, lake Magadi; the shore of the lake & alkalophile \\
\hline Verticillium zaregamsianum & $\begin{array}{c}\text { V201 } \\
(\text { CBS 137621) }\end{array}$ & Transbaikalia; lake & alkalitolerant \\
\hline
\end{tabular}

\subsection{Culture Media}

We used alkaline malt agar of standard composition, as well as three modifications of alkaline malt agar to produce liquid media different in the protein source [8]. The mineral component of these media in all three modifications was identical to that of alkaline malt agar. The composition of the nutrient component, in addition to the yeast extract, included either malt extract $\left(15^{\circ}\right.$ on the Balling scale), casein, or peptone.

Two components were sterilized and mixed similarly to the preparation of the alkaline malt agar. The mineral and nutrient components were sterilized for $1 \mathrm{~h}$ in an autoclave at $0.5 \mathrm{ATI}$, and mixing was performed in a flask with the nutrient component in a sterile laminar box at $50-60{ }^{\circ} \mathrm{C}$.

\subsection{Obtaining Submerged Cultures}

The fungal cultures were stored on slanted alkaline malt agar in a cold room at $4{ }^{\circ} \mathrm{C}$. In a laminar box, agarized blocks with surface mycelium were transferred from slanted agar (alkaline malt agar) to $150 \mathrm{~mL}$ Erlenmeyer flasks containing $50 \mathrm{~mL}$ of liquid alkaline fermentation medium and placed on an orbital shaker at $25^{\circ} \mathrm{C}$; the rotation speed was $250 \mathrm{rpm}$.

\subsection{Measuring the Enzymatic Activity of Proline-Specific Peptidase}

The activity of PSP was measured spectrophotometrically. A total of $175 \mu \mathrm{L}$ of the universal buffer (UB) with a given $\mathrm{pH}$ [23] was placed in a well of a 96-well polystyrene plate for enzyme immunoassay, then $20 \mu \mathrm{L}$ of the test filtrate and $5 \mu \mathrm{L}$ of a chromogenic substrate with a p-nitroanilide label $(\lambda=405 \mathrm{~nm})$ were added. The total volume of the reaction mixture in each well of the plate was $200 \mu \mathrm{L}$. In the control wells, the culture fluid was replaced with $20 \mu \mathrm{L}$ of UB. Plates with the reaction mixture were incubated in an ELx800 spectrophotometer at $37^{\circ} \mathrm{C}$ for 45 to $120 \mathrm{~min}$ in the mode of kinetic analysis of the optical density $(\lambda=405 \mathrm{~nm})$; the optical density of the reaction mixture was measured every 5 or $10 \mathrm{~min}$, starting from the moment of adding the substrate (zero moment, which was considered as negative control). Gen5 BioTek software was used to work with the spectrophotometer and the obtained data were processed in MO Excel 2018 program.

We used a chromogenic substrate with a $p$-nitroanilide label at the $C$-end that is specific to dipeptidyl peptidase 4 (DPP4), namely, Ala-Pro- $p$ Na. The substrate was dissolved in dimethylformamide at a concentration of $10 \mathrm{mM}$. The amount of the enzyme per $1 \mathrm{mg}$ of dry mycelium mass, which, when the substrate was hydrolyzed under the specified incubation conditions, increased the optical density of the solution by $0.01 \mathrm{in} 1 \mathrm{~h}$ at $405 \mathrm{~nm}$, 
was taken as a unit of enzymatic activity. To obtain dry biomass, the filter paper with mycelium was placed in an oven at a temperature of $80^{\circ} \mathrm{C}$ for $2 \mathrm{~h}$, after which it was cooled and weighed; the procedure was repeated until a constant weight was reached. The dry mass of the mycelium was calculated by subtracting the mass of the control paper filter that was pre-weighed and subjected to a similar incubation in an oven.

\subsection{Optimizing the Culture Medium and Mycelium Cultivation Period}

Mycelia of S. alkalinus F11, S. magadiensis B39, and S. tronii MAG3 were grown for 10 days in three alkaline fermentation media containing three alternative protein sources (barley malt, casein, and peptone). When the mycelium was formed, the culture fluid filtrates were prepared and the activity of DPP4 was measured. The peptone medium with the highest DPP4 activity was used in further experiments. To determine the optimal cultivation period, these strains were grown on the peptone culture medium for 4,7 , $11,14,18,19,21$, and 24 days, after which the culture fluid filtrates were prepared and DPP4 activity was measured. The culture filtrate was separated from the mycelium after incubation on an orbital rocker by double filtration through filter paper, after which the filtered liquid was repurified by centrifugation $(6000 \mathrm{rpm}, 10 \mathrm{~min})$. To prevent biological contamination, $8 \%$ sodium azide $\left(2.5 \mu \mathrm{L} / \mathrm{mL} \mathrm{NaN}_{3}\right)$ was added to the resulting filtrate. The filtrates were stored at $4{ }^{\circ} \mathrm{C}$.

\subsection{Determination of the $p H$ Activity Optimum of DPP4}

A total of $20 \mu \mathrm{L}$ of the solution containing the test PSP (14-day culture fluid filtrate), $175 \mu \mathrm{L}$ of UB of the selected acidity to obtain the required $\mathrm{pH}(3.1-9.5)$, and $5 \mu \mathrm{L}$ of the chromogenic substrate were added to the well of a polystyrene plate. The resulting reaction mixture was analyzed spectrophotometrically following the procedure described above.

\subsection{Determiniation of the $p H$ Stability of DPP4}

A total of $20 \mu \mathrm{L}$ of the solution containing the test PSP (14-day culture liquid filtrate) and the given volume of UB with the selected acidity were added to the well of a polystyrene plate to obtain the required $\mathrm{pH}$ (2.0-13.0). The resulting solution was incubated for 60 min with constant stirring on a shaker (300 rpm); then, UB with the selected pH was added to the volume of $195 \mu \mathrm{L}$ to obtain a $\mathrm{pH}$ of the incubation mixture of 7.5 (the optimal $\mathrm{pH}$ for the PSP from the previous experiment). Then the resulting mixture was mixed, $5 \mu \mathrm{L}$ of chromogenic substrate was added, and kinetic analysis of the enzymatic reaction was performed using a spectrophotometer.

\subsection{Determination of PSP Stability in the Presence of $\mathrm{NaCl}$}

A total of $175 \mu \mathrm{L}$ of $\mathrm{UB}$ ( $\mathrm{pH} 7.5$ ) with varying $\mathrm{NaCl}$ concentrations: $2 \mathrm{M}, 3 \mathrm{M}, 4 \mathrm{M}, 5 \mathrm{M}$, and $6 \mathrm{M}$ were added to $20 \mu \mathrm{L}$ of the test solution. After adding the buffer, the enzymatic reaction was started using $5 \mu \mathrm{L}$ of the chromogenic substrate, and the kinetics of the colored product formation was observed using a spectrophotometer. The same reaction mixture without $\mathrm{NaCl}$ served as a control.

\subsection{Studying the Effect of Peptidase Inhibitors on PSP Activity}

A total of $20 \mu \mathrm{L}$ of the culture filtrate, $170 \mu \mathrm{L}$ of the universal buffer ( $\mathrm{pH} 7.0)$, and $5 \mu \mathrm{L}$ of the inhibitor stock solution were initially placed in the well of the plate. The resulting mixture was incubated at room temperature for $20 \mathrm{~min}$, after which $5 \mu \mathrm{L}$ of the chromogenic substrate was added and the kinetic analysis of the enzymatic reaction was performed.

All experiments were carried out in 3 replicates. Average values of peptidase activities and standard deviations were calculated. 


\section{Results and Discussion}

\subsection{Bioinformatic Analysis of Amino Acid Sequences of PSP of Higher Fungi}

To determine the prevalence of PSP homologs in dikaryomycetes, 42 genomes of various ascomycetes and basidiomycetes were analyzed. In total, 10 different PSPs were found in the species, including homologs of human APP1, CND, DPP4, LAP, prolyl oligopeptidase (POP), and prolidase (XPD). Homologs of DPP4 and APP1 were found in the genomes of almost all selected species, suggesting their important functional significance, while homologs of fibroblast activation protein (FAP), DPP6, DPP8, DPP9, DPP10, and APP2 were not found in the fungal genomes (Table 1).

Some of the detected homologs were shown to specifically belong to certain taxa, which allows us to consider them as potential markers. Thus, LAP and POP homologs were found in the genomes of all the studied basidiomycete species, while, among ascomycetes, only 2 of the 32 analyzed species had such homologs, namely, the entomopathogenic mycelial fungus Beauveria bassiana and the soil yeast Saitoella complicata. Notably, taxonomically similar representatives, such as Cordyceps confragosa and Metarhizium anisopliae in the first case, and Taphrina deformans in the second one, lacked homologs of both these enzymes. Another typical example of the taxonomic specificity of PSP was the absence of EPR homologs of $A$. niger in the genomes of representatives of the Saccharomycotina subdivision that have a yeast life form or mycelial-yeast dimorphism. All the studied fungal species had homologs of human DPP4.

Out of the three different forms of prolyliminopeptidase (PIP) found in the genomes of higher fungi, PIP1, homologous to the A. sobria enzyme, was found in 28 species of ascomycetes and agaricomycetes, while rust and smut fungi lacked this type of PIP. PIP1 is a classical serine peptidase consisting of a single domain of the alpha/beta hydrolase superfamily. PIP2, homologous to the L. delbrueckii enzyme, occurred in six ascomycete species in one copy, and in four agaricomycete genomes in several copies (up to eight in the Daedalea quercina genome). PIP2 also consists of a single domain, Pro_imino_pep_2, with no signal peptide or transmembrane regions. PIP3 homolog of D. carota was found in all studied basidiomycetes (including rust and smut fungi) and only in four representatives of ascomycetes. The domain structure of PIP3 coincides with that of PIP1; the signal peptide and transmembrane regions were also absent.

In some cases, the data indicate the environmental specificity of the PSP. Thus, prolidase (XPD) homologs were found in 41 of the 42 genomes analyzed, while the absence of such homologs is characteristic of entomopathogenic fungus Hypocrella siamensis that specifically infects scale insects and whiteflies. Other examples of PSP ecological specificity include the multicopy nature of PIP homologs in wood-degrading basidiomycetes (for example, in Daedalea quercina and Calocera cornea).

Active sites of detected PSP are largely conserved between humans and fungi. The homologs of serine PSPs retain a conservative triad of amino acid residues, and the homologs of metallopeptidases have binding sites with metal ions and substrates. In contrast to insects, the studied fungi lack inactive homologs, i.e., homologs with substitution in the catalytic triad. Figure 1 shows an example of the alignment of conservative DPP4 sites in representatives of various subdivisions of higher fungi in relation to human DPP4. 


\begin{tabular}{|l|c|c|c|c|c|c|c|c|c|c|c|c|c|c|c|c|c|c|c|c|c|c|c|c|c|}
\hline Taphrina deformans CCG81671.1 & W & G & W & S & F & G & G & - & G & T & G & D & D & N & V & - & D & S & D & H & S & I & Y \\
\hline Saccharomyces cerevisiae AJT99000.1 & W & G & W & S & Y & G & G & - & G & T & F & D & D & N & V & - & D & S & D & H & S & I & R \\
\hline Saccharomyces cerevisiae AJU16581.1 & F & G & W & S & Y & G & G & - & G & T & G & D & D & N & V & - & D & S & D & H & S & I & R \\
\hline Sodiomyces alkalinus ROT37187.1 & W & G & W & S & F & G & G & - & G & V & A & D & D & N & V & - & D & S & D & H & S & I & Y \\
\hline Sodiomyces alkalinus ROT38925.1 & F & G & W & S & Y & G & G & - & G & L & G & D & D & N & V & - & D & S & D & H & S & I & V \\
\hline Puccinia graminis XP003335073.2 & W & G & W & S & Y & G & G & - & G & S & A & D & D & N & V & - & D & S & D & H & S & I & S \\
\hline Ustilago maydis XP011391995.1 & W & G & W & S & Y & G & G & - & G & S & A & D & D & N & V & - & D & S & S & H & S & V & S \\
\hline Lentinula edodes GAW08536.1 & W & G & W & S & Y & G & G & - & G & S & G & D & D & N & V & - & D & S & D & H & T & I & T \\
\hline Homo sapiens P27487 & W & G & W & S & Y & G & G & - & G & T & A & D & D & N & V & - & D & E & D & H & G & I A \\
\hline
\end{tabular}

Figure 1. Alignment of conservative DPP4 fragments close to active site in representatives of various subdivisions of higher fungi in relation to human DPP4. Substitutions found in fungi are grayed out, the amino acid residues of DPP4 Homo sapiens are highlighted in black, the conservative amino acid triad is highlighted in bold. Amino acid residue numbers are given for DPP4 H. sapiens.

The isoelectric points of most of the identified PSP homologs calculated using the online resource Isoelectric Point Calculator are in the range of 5-6. The exceptions are EPR homologs, one third of which, according to the calculations, are characterized by charge loss at $\mathrm{pH} 4-5$, and APP1 homologs, half of which have an isoelectric point value of 8-9. For example, similar APP1 homologs are typical of all the studied species of the Agaricomycotina subdivision. Since the majority of the found PSP homologs possess neither a signal peptide, nor a transmembrane site, nor a nuclear localization signal, they presumably have either a cytoplasmic localization or at least a cytoplasmic transport pathway. Notably, if two DPP4 homologs are present in ascomycetes, one of them often contains a signal peptide sequence, and the second one contains a transmembrane domain. These homologs probably have different localization and perform different functions, i.e., they are paralogs.

To assess the evolutionary relationship of DPP4, we reconstructed a phylogenetic tree of its homologs (Figure 2). In this tree two distinct groups of homologs differing in the presence of a signal peptide can be distinguished. Secreted forms are found exclusively in the Pezizomycotina subdivision in the Ascomycota division, while transmembrane forms are found in all six subdivisions of higher fungi. Transmembrane homologs, in turn, are grouped according to the taxonomic position of objects into clades corresponding to the divisions Basidiomycota and Ascomycota, and further into subdivisions within these clades. Thus, the duplication of the DPP4 gene may have occurred in the early evolution of the Pezizomycotina group, resulting in subsequent diversification of paralogs into transmembrane and secreted forms. Furthermore, this phylogenetic tree explains why FAP homologs are absent in the analyzed fungal genomes. Based on the available data, the DPP4 and FAP enzyme evolutionary lines might have parted after the separation of the fungal and animal evolutionary lines, which is manifested in the close clustering of the human and bovine FAP orthologs, as well as the human and porcine DPP4 orthologs. Thus, fungal homologs of DPP4 can be considered as homologs of the common ancestral enzyme for FAP and DPP4. 


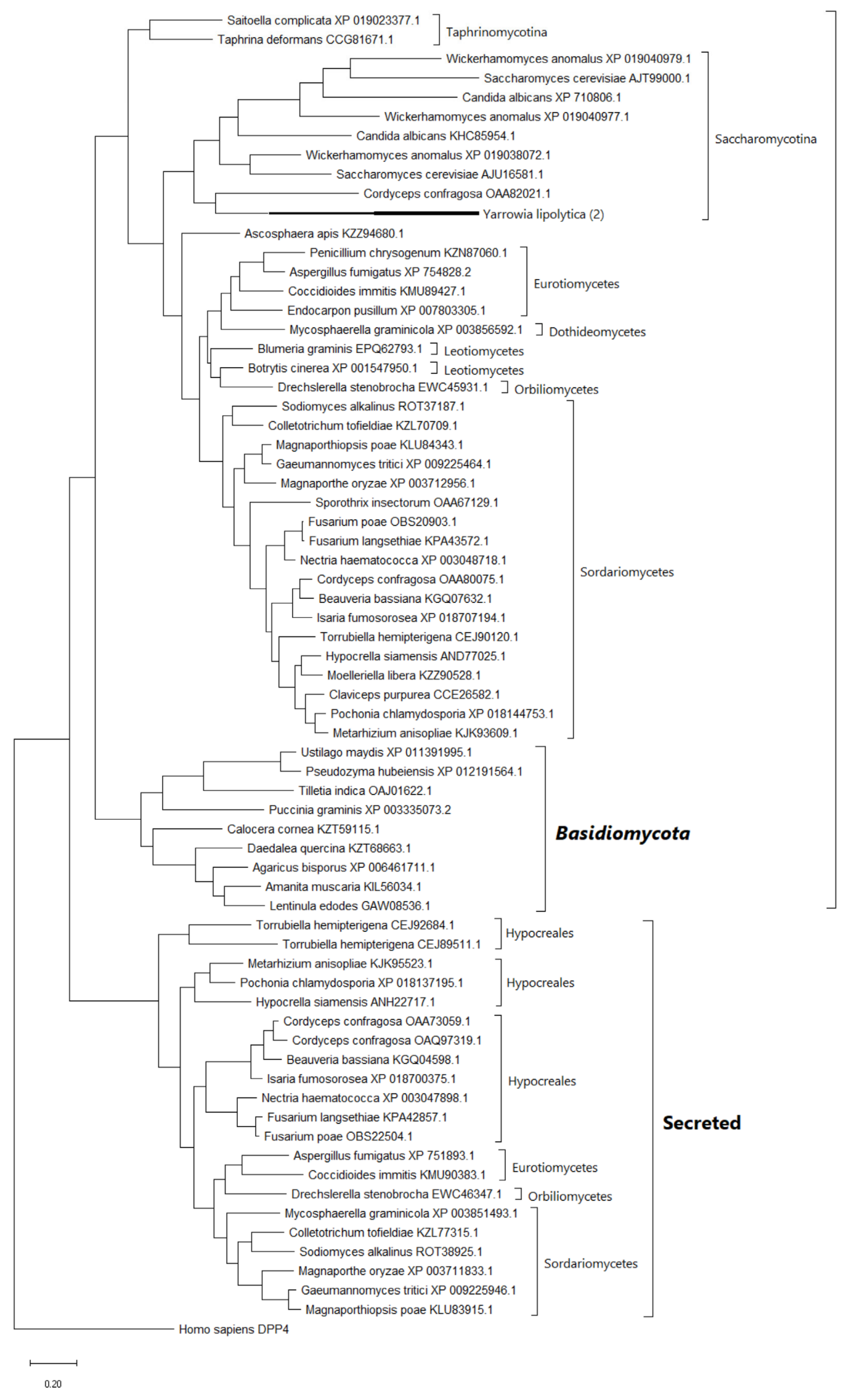

Transmembrane

Figure 2. The cladogram of DPP4 homologs constructed by the ML method. 
The bioinformatic analysis of the whole genome of the alkaliphile S. alkalinus F11 conducted using the Protein BLAST service showed the presence of nine homologs of the known PSPs found in representatives of various kingdoms of nature (humans, plants, fungi, and bacteria), including two homologs capable of cleaving proline CND (Table 1). Thus, according to the data obtained, S. alkalinus contained two homologs of the DPP4 gene, the larger one of which (ROT37187.1) contained a fragment encoding the transmembrane region, while the shorter one (ROT38925.1) lacked this motif but encoded an N-terminal signal peptide. The calculated isoelectric points of the DPP4 protein homologs of this strain lay close to each other (4.80 and 4.66), but the length of the molecules differs by 145 amino acids, and their masses are 106.0 and $87.5 \mathrm{kDa}$, respectively. Both homologs contained the conservative N-terminal domain DPP_IV in the first third of the amino acid sequence and the prolyl oligopeptidase domain Peptidase_S9 near the C-terminus. The comparison of the active centers of these homologs with the active center of human DPP4 did not reveal any strong functional differences in the amino acid environment of the conservative triad of serine, aspartic acid, and histidine residues characteristic of serine peptidases.

In S.alkalinus, the potential homolog of acidic prolyl endoprotease of $A$. niger (ROT41790.1) had an estimated molecular weight of $44.8 \mathrm{kDa}$ and an isoelectric point characteristic of homologs of this enzyme being equal to 4.6. No specific conservative domains were found in this homolog, but the active center contained a conservative triad of amino acid residues. The amino acid sequence of this homolog was devoid of a signal peptide and transmembrane sites, as well as of a nuclear localization signal, which suggested its localization in the cytoplasm.

One homolog of human aminopeptidase P1 (ROT40160.1) was also found in the genome of S. alkalinus F11. As this homolog lacked transmembrane sites and a signal peptide, it is most likely to be localized in the cytoplasm. The APP1 homolog and its ortholog in the human body have all the amino acid residues involved in the co-ordination of manganese ions in the active center of enzymes, which suggested the enzymatic function of this homolog. The isoelectric point of the homolog was 5.7, and the estimated molecular weight was $68.6 \mathrm{kDa}$. The conserved domains found in this sequence are typical of peptidases from the M24 family (the AMP_N structural domain at the N-end of the molecule and the domain with the prolidase reaction center at the $\mathrm{C}$-end).

The same family of metallopeptidases included three homologs of human prolidase (ROT42762. 1, ROT34876. 1, and ROT38161. 1), whose molecular weights were 56.9, 49.6, and $49.6 \mathrm{kDa}$, respectively. As in the previous case, SignalP and TMHMM analyses did not detect signal peptides and transmembrane regions in these sequences, and active centers of these homologs were not affected by mutations. The isoelectric points of XPD homologs were also in the slightly acidic range (5.6-5.7). The detected prolidase homologs showed the presence of conservative AMP_N and prolidase domains.

Two of the peptidase homologs found in silico and able to cleave proline bonds (ROT43826. 1 and ROT41757.1) were homologs of human cytosolic nonspecific dipeptidase. Of note, despite the twofold difference in molecular mass (100.6 kDa and 52.2 kDa, respectively), all the conserved amino acid residues important for catalysis were found in both homologs. The heavier CND homolog appeared to contain a large N-terminal insertion about 470 amino acid residues long, with no specific homology with known conservative domains. Despite the significant differences in the peptide chain length, both homologs had similar isoelectric points (5.32 and 5.21, respectively). No signal peptide or transmembrane sites were found in these homologs.

\subsection{Biochemical Identification of PSP from Alkaliphilic and Alkali-tolerant Fungi}

Identification and study of the secreted PSPs were performed on five species of alkaliphilic and alkali-tolerant mycelial dikaryomycetes from the family Plectosphaerellaceae (Glomerellales; Sordariomycetes) and one alkali-tolerant species from the family Hypocreaceae (Hypocreales; Sordariomycetes). The data obtained showed that DPP4 is the most represented extracellular PSP. Studying the physiology and biochemistry of alkaliphilic and alkali-tolerant fungi is interesting as, on the one hand, it can facilitate the understanding of 
the mechanisms underlying the adaptation of these organisms to extreme environments and lead to the discovery of new and practically significant enzymes or secondary metabolites. On the other hand, it is crucial to develop measures to prevent biological damage to products by these fungi at alkaline $\mathrm{pH}$. Secretion of PSPs depended on the content of the nutrient medium. Thus, when three species of alkaliphilic fungi of the genus Sodiomyces were grown on three alkaline fermentation media (malt, peptone, casein as nitrogen sources), DPP4 was secreted in all the studied media, but different protein sources stimulated the secretion of the general activity DPP4 to a different degree (Figure 3). When the mycelium of the studied strains was grown on malt extract, it gained mass relatively quickly, but produced a relatively small amount of DPP4. At the same time, when it was grown on a medium with peptone as a nitrogen source, S. alkalinus F11, S. tronii MAG3, and S. magadiensis B39 showed the highest DPP4 activity in terms of dry mycelium mass. The selection of cultivation period for the S. alkalinus F11 strain, which was the most effective producer of PSP from the set of selected cultures, showed that the most intensive growth was recorded on 5-18 days, after which the curve of the dry mycelium mass began to reach a plateau. In the lag phase, the studied strain secreted only trace the amounts of PSP, and the most active production of peptidase occurred at the end of the logarithmic growth stage. DPP4 activity increased by day 14 of cultivation from 0 to 7 units/mg of dry mycelium, then gradually decreased to 5 units/mg of dry mycelium by day 24 of growth. DPP4 in all studied alkali-tolerants and in all alkaliphiles, respectively, had a similar pattern of changes in biochemical properties. All the observed differences were related only to the amount of secreted activity. Among the studied alkali-tolerant species, the highest DPP4 activity was found in Chordomyces antarcticus M27, which, along with S. alkalinus F11, an effective enzyme producer per dry mycelium among alkaliphiles, was used in further work. Notably, in alkaliphilic representatives of the family (strains of the genus Sodiomyces), high DPP4 activity was found not only outside the cells, but also in the cell extract; in alkali-tolerants, no noticeable accumulation of DPP4 in cells was observed.

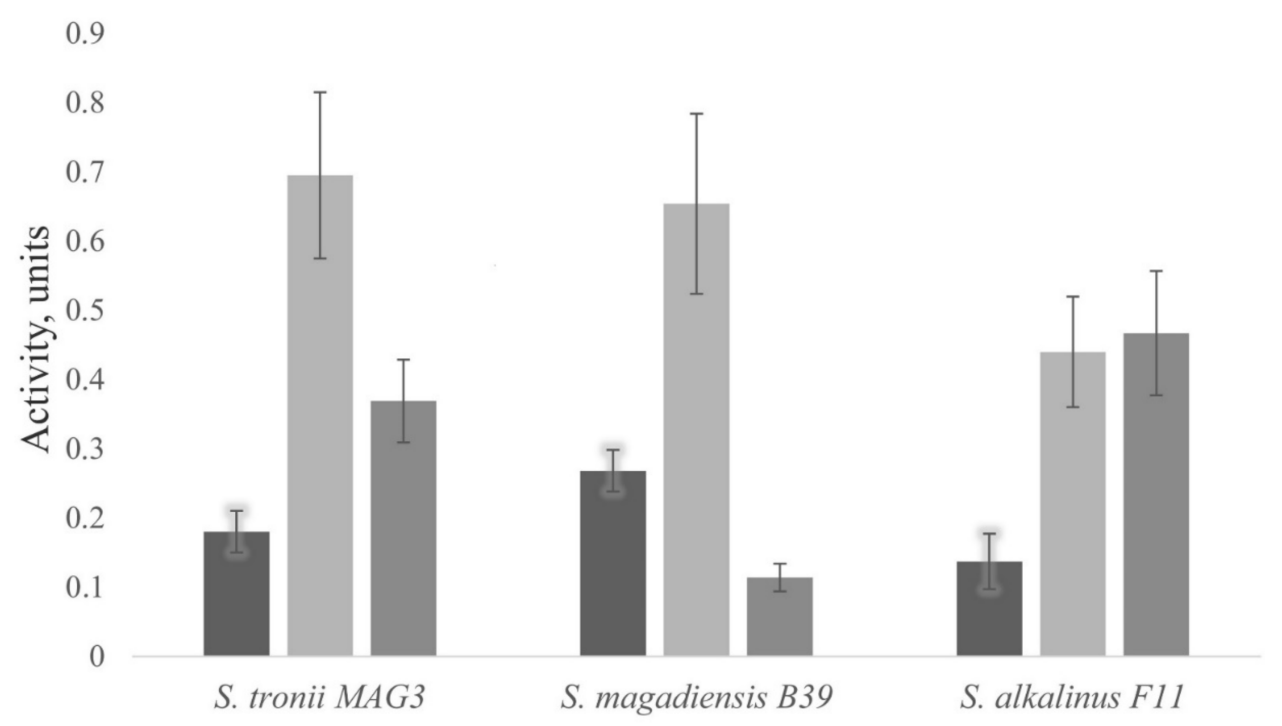

Figure 3. DPP4 activity in the culture fluid of the studied fungi. The medium with wort is black, with peptone is gray, and with casein is dark gray. The limits of the confidence interval at the $95 \%$ significance level are given.

Comparing the curves of the DPP4 activity dependence on $\mathrm{pH}$ in the strains of the alkali-tolerant C. antarcticus M27 and the alkaliphilic S. alkalinus F11 showed that, in both cases, the DPP4 of the studied species were not able to work in an acidic environment $(\mathrm{pH}<5.4)$ (Figure 4). The highest DPP4 activity in both species was shown in the $\mathrm{pH} 7-8$ region. Although $S$. alkalinus is confined to more alkaline soils, the optimal reaction of the medium for DPP4 of this species was $\mathrm{pH} 7.3$, while the enzyme of C. antarcticus with a 
wider ecological plasticity showed the maximum reaction rate at $\mathrm{pH}$ 7.7. At the $\mathrm{pH}$ values of more than 8.0, the activity of DPP4 decreased in both species. Our data indicate a slightly alkaline optimum of DPP4 activity in these species, which is consistent with the evidence obtained for homologous proteins of other fungi [24,25]. Notably, in all the experiments, DPP4 of the S. alkalinus F11 strain showed a higher enzymatic activity (approximately three times higher) compared with that of C. antarcticus M27 (Figure 4).

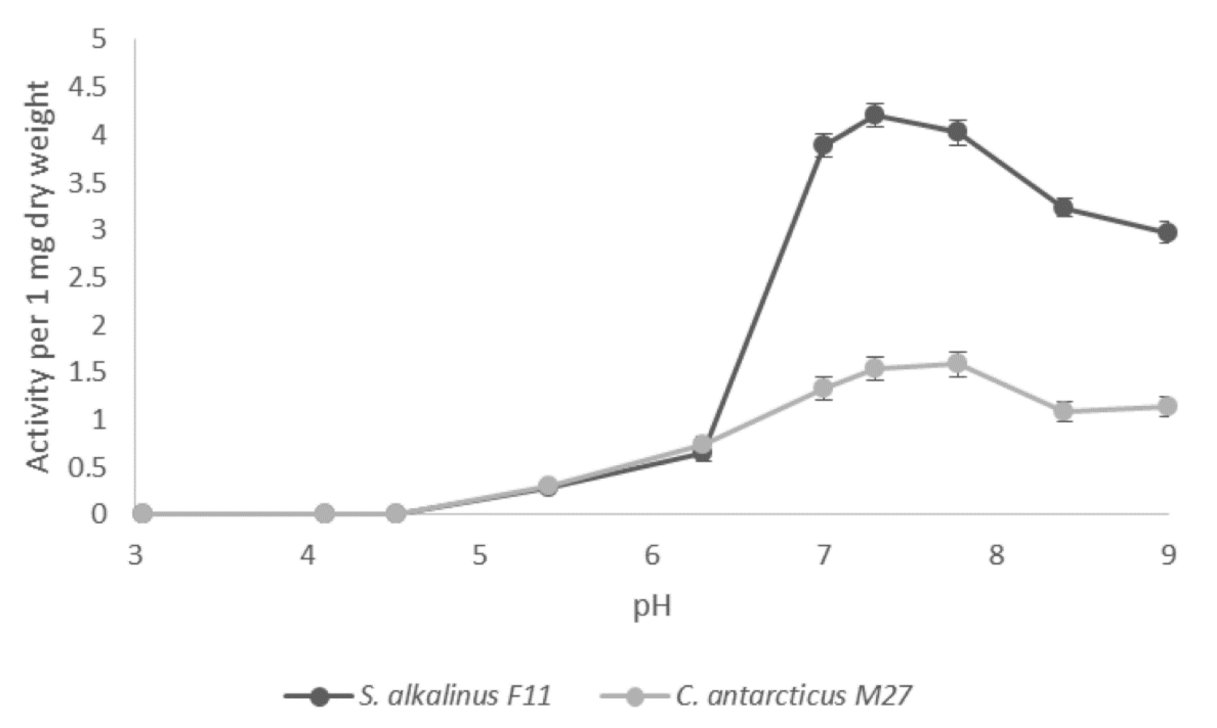

Figure 4. $\mathrm{pH}$ dependence of DPP4 activity. The limits of the confidence interval at the 95\% significance level are given.

To survive in conditions of extremely high $\mathrm{pH}$, living organisms have special enzymes that are not highly active at an alkaline $\mathrm{pH}$, but rather alkali-resistant. Measuring the DPP4 activity of F11 and M27 strains after prolonged incubation in a universal buffer of different acidity showed that both enzymes retained hydrolytic activity in a wide $\mathrm{pH}$ range. Thus, DPP4 of S. alkalinus F11 was stable in the $\mathrm{pH}$ range of 5.0-12.0 and retained 23\% of its activity after an hour of incubation at $\mathrm{pH}$ 13.0. DPP4 of the alkali-tolerant strain M27, in turn, showed a significantly greater relative activity after incubation in an acidic environment (78\% vs. $7 \%$ after incubation at $\mathrm{pH} 3.0)$, but completely denatured at $\mathrm{pH} 13.0$ (Figure 5). Since the studied DPP4 homologs are secreted enzymes, these differences may indicate that $S$. alkalinus F11 adapted to constant alkaline environment, and $C$. antarcticum M27 adapted to a wide range of $\mathrm{pH}$, with an optimum at a neutral $\mathrm{pH}$.

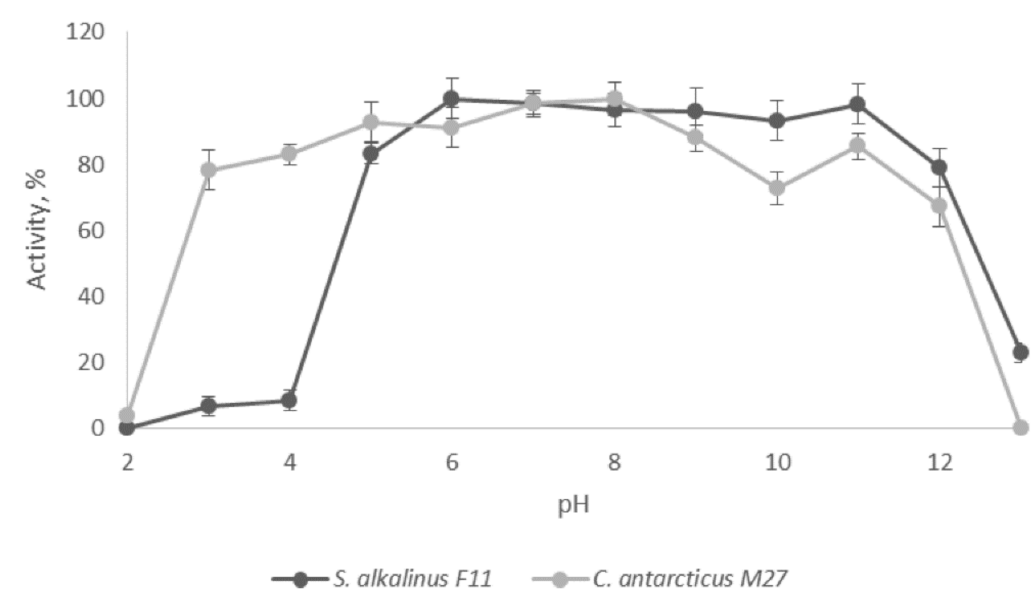

Figure 5. pH stability of DPP4. The limits of the confidence interval at the 95\% significance level are given. 
Analysis of the salt resistance of the studied PSP revealed that the activity of extracellular DPP4 strains F11 and M27 in $6 \mathrm{M} \mathrm{NaCl}$ solution at optimal $\mathrm{pH}$ values was $64 \%$ and $63 \%$ of the maximum, respectively (Figure 6). Retention of most enzyme activity at extremely high salt concentrations reflects the conditions of natural habitats where these fungi thrive. Thus, determining the stability of DPP4 in excess of $\mathrm{NaCl}$ showed that the studied peptidase is a halostable enzyme and retains activity in $\mathrm{NaCl}$ solutions close to the saturated one.

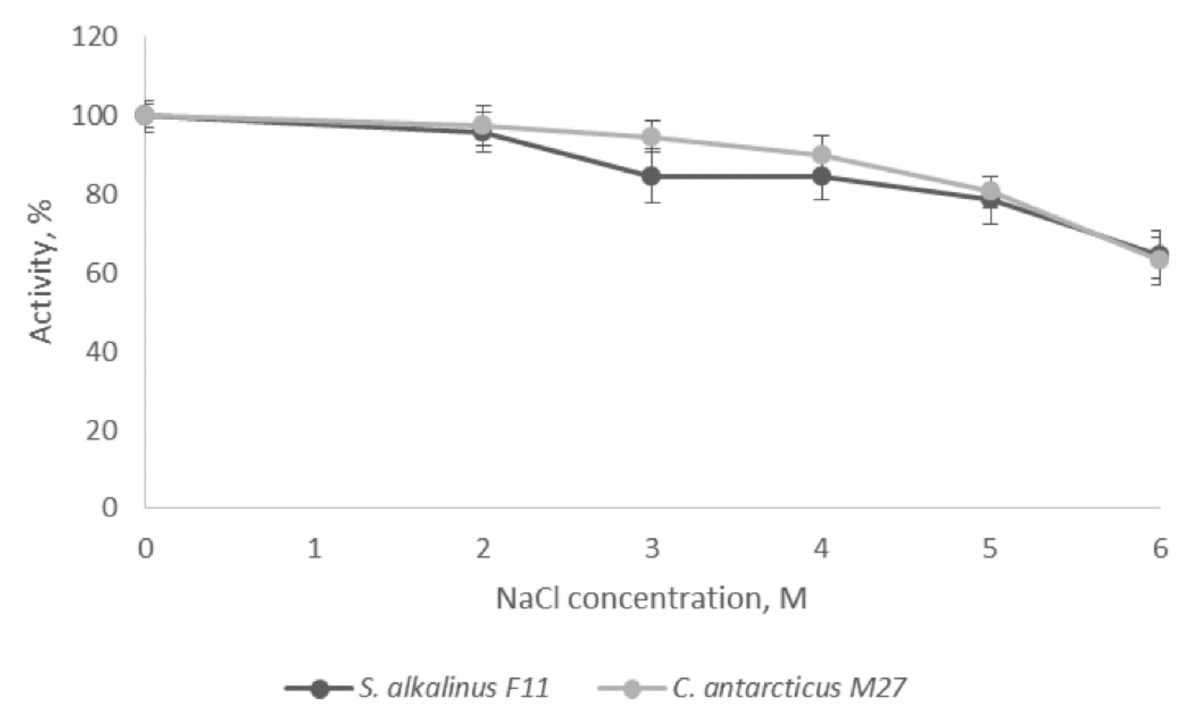

Figure 6. Salt resistance of DPP4. The limits of the confidence interval at the $95 \%$ significance level are given.

To characterize the biochemical properties of the studied DPP4, an enzyme inhibitor analysis was performed using specific peptidase inhibitors. Both S. alkalinus F11 and C. antarcticum M27 showed a marked inhibition of the enzyme by a specific serine peptidase inhibitor. The addition of $2.5 \mathrm{mM}$ phenylmethylsulfonyl fluoride (PMSF) decreased the DPP4 activity of the F11 strain to $13.7 \%$, and that of M27 strain to $9.3 \%$ of the control. The action of DPP IV inhibitors diprotin A and vildagliptin also reduced the studied enzymatic activity. In addition, the strongest inhibitory effect on S. alkalinus F11 DPP4 was produced by 0.25 $\mathrm{mM}$ diprotin A (reduced activity to $3.2 \%$ of the control), and, on C. antarcticum M27 DPP4, by $0.25 \mathrm{mM}$ vildagliptin (7.4\% of the control). At the same time, competitive PSP inhibitors, such as Ala-Pro (AP)-N-methylformamide (MF), AP-N-methyl-2-pyrrolidone (NMP), and AP-pipecolic acid (Pip), did not decrease DPP4 activity in both cases. The cysteine peptidase inhibitor iodoacetamide and the metalloprotease inhibitor EDTA also had no significant effect on the enzyme (Figure 7). The data obtained indicate that DPP4 belongs to the class of serine peptidases and determine a possible way to control its activity. 


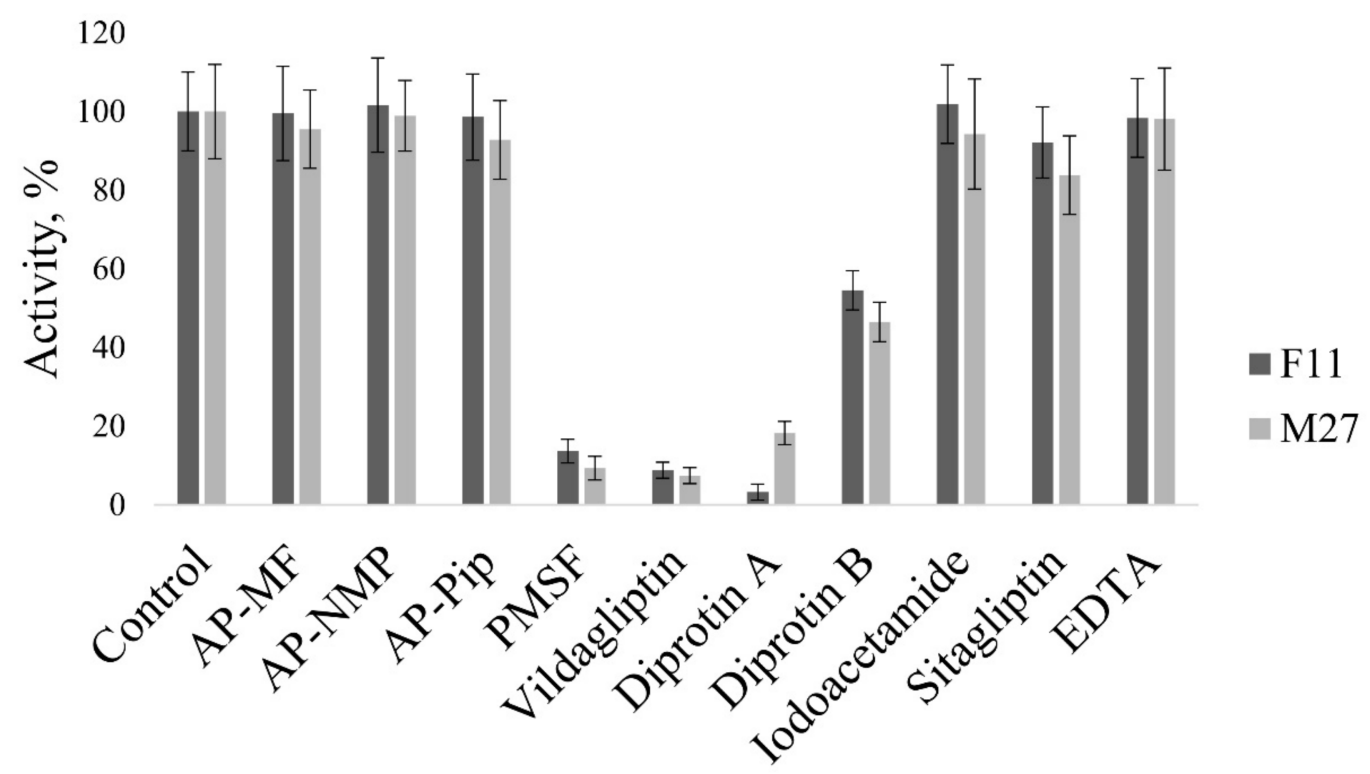

Figure 7. The effect of inhibitors on DPP4. The limits of the confidence interval at the $95 \%$ significance level are given.

\section{Conclusions}

The active development of bioinformatic methods for studying proteins and obtaining hundreds of new sequenced genomes stimulate PSP research in various taxa and facilitate the search for opportunities for the application of these peptidases. To determine the spectrum of PSPs potentially synthesized in fungal cells, a bioinformatic analysis of 42 sequenced genomes was performed, which showed that the genomes of different fungal species differ in the number and set of PSPs; for some enzymes, taxon specificity and adherence to certain ecological and trophic groups were shown. DPP4 was the only PSP present in all the studied genomes, including alkaliphilic and alkali-tolerant species. Such a representation of DPP4 in representatives of various species and genera of fungi may be evidence in favor of the conservativeness and high importance of this peptidase for their vital activity, and indicates the possibility of using fungi as producers of this enzyme. Using a specific substrate and inhibitory analysis, the enzyme was identified in culture filtrates and the properties important for its commercial use were evaluated. The enzymes from the alkaliphilic and alkali-tolerant species had several notable peculiarities, but, in both cases, the DPP4 studied were both active and stable under alkaline conditions and at high salt concentrations, which makes them good candidates for biotechnological applications and bioengineering. Furthermore, DPP4 can be used as a preparation to cleave difficult-to-hydrolyze proline-rich peptides under conditions corresponding to those of the human gut, and may, therefore, be considered as a potential candidate for the enzyme therapy of celiac disease.

Author Contributions: Conceptualization, Y.D., E.E., M.B.; methodology, E.E., I.F., V.T., G.B.; software, N.A.; validation, Y.D., I.F., G.B.; investigation, N.A., V.T.; writing—original draft preparation, Y.D.; writing-review and editing, M.B.; visualization, N.A. All authors have read and agreed to the published version of the manuscript.

Funding: This work was supported by the Russian Foundation for Basic Research (grant No. 19-0400852-a).

Data Availability Statement: The data were presented and discussed at Congress of Biochemists of Russia (2019), International Multiconference "Bioinformatics of Genome Regulation and Structure/Systems Biology $(2019,2020)$, International Scientific Conference Lomonosov" $(2019,2020)$ and are reflected in the conference materials.

Conflicts of Interest: The authors declare no conflict of interest. 


\section{References}

1. Rampelotto, P.H. Extremophiles and extreme environments. Life 2013, 3, 482-485. [CrossRef] [PubMed]

2. Selbmann, L.; Egidi, E.; Isola, D.; Onofri, S.; Zucconi, L.; de Hoog, G.S.; Chinaglia, S.; Testa, L.; Tosi, S.; Balestrazzi, A.; et al. Biodiversity, evolution and adaptation of fungi in extreme environments. Plant Biol. 2013, 147, 237-246. [CrossRef]

3. Egorova, A.S.; Gessler, N.N.; Ryazanova, L.P.; Kulakovskaya, T.V.; Belozerskaya, T.A. Stress resistance mechanisms in the indicator fungi from highly radioactive Chernobyl zone sites. Mikrobiologiia 2015, 84, 184-191. [CrossRef] [PubMed]

4. Wang, M.; Tian, J.; Xiang, M.; Liu, X. Living strategy of cold-adapted fungi with the reference to several representative species. Mycology 2017, 8, 178-188. [CrossRef] [PubMed]

5. Kladwang, W.; Bhumirattana, A.; Hywel-Jones, N. Alkaline-tolerant fungi from Thailand. Fungal Divers. 2003, $13,69-84$.

6. Grum-Grzhimaylo, A.A.; Georgieva, M.L.; Bondarenko, S.A.; Debets, A.J.; Bilanenko, E.N. On the diversity of fungi from soda soils. Fungal Divers. 2016, 76, 27-74. [CrossRef]

7. Tiquia-arashiro, S.M.; Grube, M. (Eds.) Fungi in Extreme Environments: Ecological Role and Biotechnological Significance; Springer: Cham, Switzerland, 2019; 626p. [CrossRef]

8. Grum-Grzhimaylo, A.A.; Debets, A.J.M.; van Diepeningen, A.D.; Georgieva, M.L.; Bilanenko, E.N. Sodiomyces alkalinus, a new holomorphic alkaliphilic ascomycete within the Plectosphaerellaceae. Pers. Mol. Phylogeny Evol. Fungi 2013, 31, 147-158. [CrossRef] [PubMed]

9. Grum-Grzhimaylo, A.A.; Falkoski, D.L.; van den Heuvel, J.; Valero-Jiménez, C.A.; Min, B.; Choi, I.G.; Lipzen, A.; Daum, C.G.; Aanen, D.K.; Tsang, A.; et al. The obligate alkalophilic soda-lake fungus Sodiomyces alkalinus has shifted to a protein diet. Mol. Ecol. 2018, 27, 4808-4819. [CrossRef] [PubMed]

10. Betts, M.J.; Russell, R.B. Amino acid properties and consequences of substitutions. In Bioinformatics for Geneticists; Barnes, M.R., Gray, I.C., Eds.; John Wiley \& Sons Ltd.: Chichester, West Sussex, UK, 2007; pp. 311-342.

11. Wu, G.; Bazer, F.W.; Burghardt, R.C.; Johnson, G.A.; Kim, S.W.; Knabe, D.A.; Li, P.; Li, X.; McKnight, J.R.; Satterfield, M.C.; et al. Proline and hydroxyproline metabolism: Implications for animal and human nutrition. Amino Acids 2011, 40, 1053-1063. [CrossRef] [PubMed]

12. Kõiv, V.; Tenson, T. Gluten-degrading bacteria: Availability and applications. Appl. Microbiol. Biotechnol. 2021, 105, 3045-3059. [CrossRef] [PubMed]

13. Dunaevsky, Y.E.; Tereshchenkova, V.F.; Oppert, B.; Belozersky, M.A.; Filippova, I.Y.; Elpidina, E.N. Human proline specific peptidases: A comprehensive analysis. Biochim. Biophys. Acta Gen. Subj. 2020, 1864, 129636. [CrossRef] [PubMed]

14. Stepniak, D.; Spaenij-Dekking, L.; Mitea, C.; Moester, M.; de Ru, A.; Baak-Pablo, R.; van Veelen, P.; Edens, L.; Koning, F. Highly efficient gluten degradation with a newly identified prolyl endoprotease: Implications for celiac disease. Am. J. Physiol. Gastrointest. Liver Physiol. 2006, 291, G621-G629. [CrossRef] [PubMed]

15. Schulz, K.; Giesler, L.; Linke, D.; Berger, R.G. A prolyl endopeptidase from Flammulina velutipes for the possible degradation of celiac disease provoking toxic peptides in cereal proteins. Process Biochem. 2018, 73, 47-55. [CrossRef]

16. Eugster, P.J.; Salamin, K.; Grouzmann, E.; Monod, M. Production and characterization of two major Aspergillus oryzae secreted prolyl endopeptidases able to efficiently digest proline-rich peptides of gliadin. Microbiology 2015, 161, 2277-2288. [CrossRef] [PubMed]

17. Pennington, M.W.; Dunn, B.M. Peptide Synthesis Protocols; Humana Press: Totowa, NJ, USA, 1995.

18. Protein Sequences. Available online: https://blast.ncbi.nlm.nih.gov/Blast.cgi (accessed on 22 December 2020).

19. Enzyme Similarity Tool. Available online: https:/ / efi.igb.illinois.edu/efi-est (accessed on 26 December 2020).

20. Isoelectric Point Calculator. Available online: http:/ / isoelectric.org/calculate.php (accessed on 26 December 2020).

21. Domain Assignment. Available online: http://www.cbs.dtu.dk/services (accessed on 26 December 2020).

22. Search for Conservative Domains. Available online: https://www.ncbi.nlm.nih.gov/Structure/bwrpsb/bwrpsb.cgi (accessed on 28 December 2020).

23. Britton, H.T.S.; Robinson, R.A. Universal buffer solutions and the dissociation constant of veronal. J. Chem. Soc. 1931, 1456-1462. [CrossRef]

24. Doumas, A.; van der Broek, P.; Affolter, M.; Monod, M. Characterization of the prolyl dipeptidyl peptidase gene (dppIV) from the koji mold Aspergillus oryzae. Appl. Environ. Microbiol. 1998, 64, 4809-4815. [CrossRef] [PubMed]

25. Cooper, K.G.; Woods, J.P. Secreted dipeptidyl peptidase IV activity in the dimorphic fungal pathogen Histoplasma capsulatum. Infect. Immun. 2009, 77, 2447-2454. [CrossRef] [PubMed] 